\title{
Creative (dis)agreement in ergonomics
}

Neville A. Stanton $\Sigma^{*}$ and Rob B. Stammers

\begin{abstract}
This Article does not have an abstract.
\end{abstract}

*Author for correspondence.e-mail:neville.stanton@brunel.ac.uk 


\section{Introduction}

In this second invited peer commentary issue of Ergonomics, we are pleased to start with paper from Professor John Annett on the use and abuse of subjective rating scales. As with the target paper in the first of these peer commentary issues (Dowell and Long 1998), Annett challenges the basis of some fundamental assumptions in Ergonomics. The criteria for a target paper (Stanton and Stammers 1998) are that the body of work should:

- be of broad scope overarching all areas of Ergonomics,

- have significant ramifications for the discipline,

- contain some element of contemporary controversy,

- offer unification of methodology and theory,

- meaningfully integrate a body of research.

As before, the target paper is followed by a succession of peer commentary papers and concluded with a response paper by the author of the target paper. It is intended that the peer commentary issues of Ergonomics will capitalize upon the benefits of creative disagreement, by engaging the research community in debate of current controversies in the discipline. We hope that other readers will also find this endeavor worthwhile.

\section{Ergometrics in Ergonomics}

It is difficult to find an aspect of the discipline not touched by subjective rating scales. In fact, a review of papers published in this journal in 2000 revealed that of the 134 papers published, 40 reported on studies that involved subjective methods and techniques (table1). Given that such approaches are so widely used, and that their applicability covers the broad spectrum of ergonomics research and application, subjective rating scales are an ideal topic for a target paper in a peer commentary issue of the journal. In his target paper, Annett identifies four key issues for subjective rating scales: subjectivity, measurement, multiple dimensions and fitness. First, he argues that subjectivity is all pervasive. Even so-called objective methods are inevitably influenced by subjectivity. Second, he argues that subjective judgment can be mapped onto ordinal scales for the purpose of measurement quite successfully. This offers the ergonomist a means of collecting data about a phenomenon that might not otherwise be available. Third, he argues that it is possible to have both physical and subjective components of multidimensional constructs. The critical issue is to establish their validity. He reviews a variety of ways by which this can be done. Finally, he argues that care should be taken in making sure that a subjective rating scale is fit-for-purpose. Rather than selecting a technique because of its ease of administration, researchers need to determine that the approach is appropriate and will yield useful data for the study they are undertaking.

Table 1. Analysis of the number of studies using subjective rating scales reported in Ergonomics for the year 2000.

\begin{tabular}{lccc}
\hline $\begin{array}{l}\text { Scales/ Human- } \\
\text { computer }\end{array}$ & $\begin{array}{c}\text { Physical and } \\
\text { Domain }\end{array}$ & $\begin{array}{c}\text { Transportation } \\
\text { interaction }\end{array}$ & physiological \\
\hline Comfort & 3 & 2 & 7 \\
Confidence & 2 & 0 & 0 \\
Fatigue & 0 & 1 & 3 \\
Mood & 1 & 3 & 4 \\
Performance & 1 & 4 & 4 \\
Preference & 2 & 1 & 2 \\
Satisfaction & 0 & 5 & 0 \\
Workload & 2 & 2 & 5 \\
Usability & 0 & 2 & 1 \\
\hline
\end{tabular}


At the heart of the debate on subjective rating scales is the issue of intersubjectivity. Maximizing the degree of agreement between independent observers of the same event is one way of increasing the reliability of subjective rating scales. In the search for agreement, Annett shows that there are many potential sources of bias. He offers some technical solution to minimize the degree of disagreement, such as additive conjoint measurement and cross-modal matching. As with the reliability of the measurement approach, the validity also requires confirmation. Construct and predictive validity may exist independently of each other. Annett shows that whilst most approaches can demonstrate construct validity, few can claim empirical evidence of predictive validity. This is an obvious challenge for the discipline, and there is much to be done (see, for example, the studies conducted by Stanton and Young 1999).

Despite this, there is a positive feeling to the outcome of his paper. Annett is very supportive of the research and development work being undertaken in the domain of subjective rating scales and argues that there is much to comment on their continued use. This is qualified by the prudent approach taken in the development of multidimensional scales that are grounded in Ergonomics theory, verified in terms of empirical reliability and validity, and well-researched in terms of utility for the intended domain of application. To paraphrase Annett, the proper development and prudent application of subjective rating scales is by no means easy, but it is well worth it.

\section{Future of peer commentary}

As the peer commentaries in this special issue show, there is a mixture of both agreement and disagreement. This is likely to foster further debate on subjective rating scales in Ergonomics. We are optimistic that the peer commentary ball is well and truly rolling now, and would like to invite other researchers to consider submitting papers for this treatment. To be considered for a peer commentary edition of Ergonomics, the author(s) must also offer a clear rationale for inclusion in this form of communication. The rationale must be included in the covering letter (as this extensive form of communication involves the time and thought of so many) and a list of no fewer than 12 proposed commentators should be provided. Whilst it is a brave researcher that submits a target article in the peer commentary issue, as we have discovered, development of the discipline requires that such individuals serve as catalysts for progress.

\section{References}

DoweLL, J. and LonG, J. 1988, Conception of the cognitive engineering design problem, Ergonomics, 41, 126-139.

Stanton, N. A. and Stammers, R. B. 1998, Peer commentary in Ergonomics, Ergonomics, 41, 121-125.

Stanton, N. A. and Young, M. S. 1999, A Guide to Methodology in Ergonomics 